\title{
RESPONS PERTUMBUHAN BIBIT PULAI (Alstonia scholaris) TERHADAP CUKA KAYU DAN NAUNGAN
}

\author{
(Response to growth of seedlings of pulai against wood vinegar and shade Alstonia scholaris)
}

\author{
Feronika Mery, Hanna Artuti Ekamawanti, Dwi Astiani
}

Fakultas Kehutanan Universitas Tanjungpura Jl. Daya Nasional, Pontianak 78124

E-mail : feronika.Lovejesus@gmail.com

\begin{abstract}
Pulai (Alstonia scholaris) is a fast growing local species that can be used rehabilitation activities on peat swamp forest. This study aims to obtain information application the response of growth and quality of pulai seedlings to wood vinegar and shade. The research was carried out at orchid exsitu observation site stock and community service and in the silvicultural laboratory of Faculty of Forestry. This study applied an experimental method with a split plot design with a complete randomized design (CRD). The treatment consisted of two factors, "shading" as the main factor and kind of organic vinegar as sub factor. The results obtained were based on observations 12 weeks after planting, the growth percentage of pulai seedlings for the $100 \%$, while ofthen variables in this study had no effect. The main factor is organic fertilizer with 2 levels: chemical fertilizer and wood vinegar, while the shade factor is a main factor that less interest. Results showed that the response of height growth was significantly higher $13.0 \%$ to chemical fertilizer than wood vinegar when planted in a shadeless condition. However, if planted in conditions with a shade of 60\%, the response was no different. The response of leaves growth to fertilizer is significant when planted under different shade conditions. In the condition without shade, the response of leaves is $11.8 \%$ higher compared to wood vinegar. Conversely, in condition with shading 60\%, the response the number of leaves growth on wood vinegar was $13.0 \%$ higher than that of chemical fertilizer. In this study, the concentration of wood vinegar as much as $4 \%$ was not effective enough to increase the enhance of pulai seedlings.
\end{abstract}

Keywoards: Organic vinegar, pulai seedlings, shade

\section{PENDAHULUAN}

Hutan rawa gambut adalah salah satu tipe hutan rawa yang merupakan ekosistem yang spesifik dan rapuh, baik dilihat dari segi habitat lahannya yang berupa gambut dengan kandungan bahan organik dan jenis tanahnya tergolong organosol, podsol maupun humus. Namun dari tahun ke tahun terjadi degradasi hutan yang semakin meningkat akibat pembalakan, kebakaran dan perambahan hutan. Data terakhir diperoleh bahwa laju kerusakan hutan maupun di luar kawasan hutan mencapai 2,83 juta hektar/tahun.Khusus untuk rawa gambut diIndonesia diperkirakan 50\% mengalami degradasi (Badan Planologi Kehutanan 2005). Kegiatan rehabilitasi dihutan rawa gambut, untuk ketebalan gambut yang sangat bervariasi dari yang dangkal sampai dengan yang dalam, kondisi dan tinggkat pelapukan gambut serta penggenangan air akan memberikan perlakuan yang bermacam-macam dalam pemilihan jenis tanamannya. Hutan rawa gambut mempunyai peluang besar untuk 
dipulihkan,suatu cara untuk memulihkan hutan rawa gambut yang terdegradasi adalah melalui restorasi dengan sistem silvikultur. Syarat restorasi yaitu dengan menggunakan jenis-jenis tanaman lokal. Salah satu jenis tanaman lokal yang potensial adalah pulai (Alstonia scholaris). Pulai merupakan jenis tanaman kehutanan yang hidup didaerah hutan rawa gambut (Rochamayanto et al. 2010). Kegiatan merestorasi hutan rawa gambut yang telah terdegradasi tidak lepas dari kegiatan penyediaan bibit.

Faktor yang mempengaruhi fase pembibitan adalah memperhatikan faktor pertumbuhan bibit di antaranya adalah naungan dan pupuk. Namun apakah pemberian naungan dan pupuk dapat menentukan kualitas pertumbuhan bibit belum diketahui pengaruhnya. Lahan ternaungi merupakan kondisi lingkungan yang kurang menguntungkan bagi jenis tertentu seperti pulai, meskipun ada beberapa jenis tanaman yang cukup toleran terhadap naungan. Masing-masing jenis tanaman akan memiliki respons yang berbeda terhadap naungan. Pengalaman di BPDASHL Kapuas, pembibitan pada tanaman pulai menggunakan naungan buatan paranet $70 \%$. Di sisi lain tanaman pulai tergolong jenis tanaman intoleran yaitu tidak suka naungan. Pada penelitian ini digunakan paranet $60 \%$. Selain naungan, faktor yang dapat mempengaruhi pertumbuhan bibit adalah pupuk.

Pupuk merupakan faktor yang penting dilakukan karena dengan suplai hara dari pupuk dapat memacu pertumbuhan akar dan dapat meningkatkan daya tahan tanaman terhadap kekurangan air (water stress), suhu yang rendah atau serangan penyakit(Oliet 2004). Pupuk yang umum digunakan saat ini terutama di BPDASHL Kapuas adalah pupuk kimia (NPK). Sementara dalam proses pemeliharaan bibit tidak harus menggunakan pupuk kimia, namun pengunaan cuka kayu dapat menjadi alternatif sebagai pemupukan. Pemupukan bertujuan untuk meningkatkan produktivitas pembibitan pulai di persemaian. Cuka kayu berfungsi sebagai pemacu pertumbuhan tanaman, kandungan yang terdapat di dalam cuka kayu sebagian besar terdiri dari air dan komponen kimia (Anonim 2001). Namun permasalahannya apakah penggunaan naungan $60 \%$ dan cuka kayu dapat memacu pertumbuhan bibit pulai di persemaian, belum diketahui pengaruhnya. Oleh karena itu, perlu dilakukan penelitian mengenai penggunaan naungan dan cuka kayu.

\section{METODE PENELITIAN}

Penelitian akan dilakukan di rumah kasa di Lembaga Penelitian dan Pengabdian Kepada Masyarakat dan di Laboratorium Silvikultur Fakultas Kehutanan dengan waktu penelitian selama kurang lebih 3 bulan. Penelitian ini menggunakan rancangan petak terbagi (split plot design) dengan pola dasar rancangan acak lengkap (RAL). Perlakuan terdiri dari jenis naungan sebagai petak utama $(\mathrm{N})$ dan pemberiaan cuka kayu $(\mathrm{P})$ sebagai anak petak. Data utama dalam penelitian ini adalah pertambahan tinggi $(\mathrm{cm})$, pertambahan diameter(mm), jumlah daun (helai), persentase hidup tanaman (\%), biomassa bibit, rasio pucuk akar. Sebelum dilakukan analisis ragam, data akan diuji kehomogenan ragam galatnya 
menggunakan uji Bartlet ( Gaspersz 1991). Setelah diuji asumsi kehomogenan raganjutkan dengan analisis ragam, menggunakan rancangan petak terbagi dengan pola dasar RAL.

\section{HASIL DAN PEMBAHASAN}

Hasil penelitian selama 12 minggu hidup tanaman yaitu $100 \%$ dan rata-rata hasil pengukuran yang telah dilakukan terhadap pertambahan tinggi, pertambahan diameter, pertambahan jumlah daun, biomassa dan rasio pucuk akar bibit pulai dapat dilihat pada Tabel 1.

didapatkan informasi terhadap persentase

Tabel 1.Rekapitulasi hasil sidik ragam pengaruh naungan dan cuka organik pada semai pulai selama 12 minggu setelah tanam (Recapitulation of the results of the variety of effects of organic shade and vinegar on seedling for 12 weeks after planting).

\begin{tabular}{lccccc}
\hline $\begin{array}{c}\text { Sumber } \\
\text { Keragaman }\end{array}$ & $\begin{array}{c}\text { Pertambahan } \\
\text { Tinggi } \\
(\mathbf{c m})\end{array}$ & $\begin{array}{c}\text { Pertambahan } \\
\text { Diameter } \\
(\mathbf{m m})\end{array}$ & $\begin{array}{c}\text { Pertambahan } \\
\text { Jumlahdaun(helai) }\end{array}$ & $\begin{array}{c}\text { Biomassa } \\
\text { bibit(g) }\end{array}$ & $\begin{array}{c}\text { Rasio } \\
\text { pucuk } \\
\text { akar(g) }\end{array}$ \\
\hline Naungan(N) & tn & tn & tn & tn & tn \\
Pupuk (P) & tn & tn & tn & tn & tn \\
Interaksi NP & $* *$ & tn & $* *$ & tn & tn \\
\hline
\end{tabular}

Keterangan; $\mathrm{tn}=$ tidak nyata $; * *=$ nyata

Berdasarkan hasil penelitian 12 minggu setelah tanam di lapangan (Tabel 1) menunjukkan bahwa pengaruh interaksi naungan dan pupuk yang digunakan memberikan pengaruh yang nyata pada pertambahan tinggi dan jumlah daun. Sedangkan variabel lainnya (pertambahan diameter, biomassa dan rasio pucuk akar) tidak nyata. Oleh karena interaksi naungan dan pupuk pengaruhnya nyata, maka pada pertambahan tinggi dan pertambahan jumlah daun, dilakukan uji lanjut dengan beda nyata terkecil (BNT) yang hasilnya dapat dilihat pada Tabel 2 .

Tabel 2. Rerata pertambahan tinggi semai pulai selama 12 minggu setelah tanam (Average height of seedling for 12 weeks after planting)

\begin{tabular}{ccc}
\hline Naungan & \multicolumn{2}{c}{ Pupuk (anak petak) } \\
\cline { 2 - 3 } (Petak utama) & NPK $\left(\mathrm{P}_{1}\right)$ & Cuka kayu $\left(\mathrm{P}_{2}\right)$ \\
\hline & Rerata pertambahan tinggi $(\mathrm{cm})$ \\
Tanpa naungan $\left(\mathrm{N}_{1}\right)$ & $17,6 \mathrm{a}(\mathrm{A})$ & $15,2 \mathrm{~b}(\mathrm{~A})$ \\
Naungan (paranet 60\%) $\left(\mathrm{N}_{2}\right)$ & $15,2 \mathrm{a}(\mathrm{A})$ & $13,8 \mathrm{a}(\mathrm{A})$ \\
\hline & Rerata pertambahan jumlah daun (helai) \\
Tanpa naungan $\left(\mathrm{N}_{1}\right)$ & $10,2 \mathrm{a}(\mathrm{A})$ & $9 \mathrm{~b}(\mathrm{~A})$ \\
Naungan (paranet $60 \%)\left(\mathrm{N}_{2}\right)$ & $9,4 \mathrm{a}(\mathrm{A})$ & $10,8 \mathrm{~b}(\mathrm{~B})$ \\
\hline
\end{tabular}

Keterangan: Angka yang diikuti dengan notasi huruf besar yang sama (dalam kolom yang sama) dan angka yang diikuti dengan notasi huruf kecil yang sama (dalam baris yang sama)berbeda tidak signifikan dengan uji BNT pada taraf $\alpha \%$

Pada penelitian ini faktor yang dipentingkan adalah faktor pupuk, dengan 2 taraf faktor yaitu NPK dan cuka kayu, sedangkan faktor naungan tidak begitu dipentingkan. Hasil penelitian menunjukan bahwa respons pertambahan tinggi nyata 
13,0\% lebih tinggi terhadap pupuk NPK dari pada terhadap cuka kayu bila ditanam pada kondisi tanpa naungan. Namun bila ditanam pada kondisi dengan naungan $60 \%$, responsnya tidak berbeda. Respons pertambahan jumlah daun terhadap pupuk berbeda bila ditanam pada kondisi naungan yang berbeda juga. Pada kondisi tanpa naungan, respons pertambahan jumlah daun lebih tinggi 11,8\% dibandingkan terhadap cuka kayu. Sebaliknya pada kondisi dengan naunngan $60 \%$, respons pertambahan jumlah daun terhadap cuka kayu lebih tinggi 13,0\% dibandingkan terhadap

\section{Persentase Hidup Bibit Pulai}

Persentase hidup bibit pulai merupakan perbandingan antara jumlah bibit yang hidup pada akhir penelitian dengan jumlah bibit yang ditanam pada awal penelitian dikali dengan seratus persen. Persentase bibit hidup dihitung berdasarkan pengamatan yang dilakukan selama (12 MST) salah satu tanda menunjukkan munculnya daun baru. Berdasarkan jumalah bibit yang masih segar (hidup) dan tidak memperlihatkan gejala kemataian. Kriteria gejala dalam pengamatan bibit pulai yaitu mengalami gugur daun, daun yang kekuningan, dan bagian batang dan akar mulai membusuk. Berdasarkan perhitungan persentase hidup bibit pulai, pada perlakuan tanpa naungan + pupuk kimia(NPK) sebagai kontrol berkisar $100 \%$ dan pada perlakuan naungan $60 \%+$ pupuk organik (cuka kayu) berkisar $100 \%$.

\section{Pertambahan Diameter Bibit Pulai}

Hasil Rerata pertambahan diameter bibit pulai selama 12 minggu pengamatan tidak signifikan. hal ini berarti bahwa perlakuan naungan dan pupuk tidak berpengaruh nyata terhadap pertambahan diameter bibit pulai. Namun hasil penelitian Komarayati et al. (2014) menunjukkan bahwa penambahan cuka kayu 4\% selama 6 (enam) bulan mampu menghasilkan diameter anakan pohon penghasil gaharu, yaitu 18,29 $\mathrm{mm}$. bertambahnya diameter merupakan faktor penting bagi tanaman, jika pada penelitian ini cuka kayu tidak berpengaruh nyata pada pertumbuhan bibit pulai, kemungkinan ada faktor lain diantaranya adalah cahaya. Pertumbuhan tinggi dan diameter tanaman dipengaruhi oleh cahaya (Marjenah 2001).

\section{Biomassa dan Rasio Pucuk Akar}

Biomassa merupakan pertumbuhan berat kering total (akar, batang dan daun). Rerata biomassa dan rasio pucuk akar bibit pulai selama 12 minggu pengamatan tidak signifikan. Hal ini berarti bahwa. Rasio pucuk akar merupakan perbandingan antara berat kering pucuk dengan berat kering akar. Bibit dinilai siap tanam apabila memenuhi kriteria nilai RPA ada pada kisaran 2-5 (Mindawatiet al 2005).

\section{Indeks Mutu Bibit Pulai}

Berdasarkanhasil penelitian data bobot kering akar, bobot kering pucuk, tinggi dan diameter bibit pulai maka didapat hasil perhitungan nilai indeks mutu bibit. Rerata indeks mutu bibit pulai dari setiap perlakuan dapat dilihat pada Tabel 3. 
Tabel 3. Indeks mutu bibit pulai (pulai seed quality index)

Naungan
Tanpa naungan $\left(\mathrm{N}_{1}\right)$
Dengan naungan $60 \%\left(\mathrm{~N}_{2}\right)$
Nilai IMB diperoleh dari parameter
pertumbuhan tinggi, diameter,bobot
kering akar dan bobot kering pucuk.
IMB digunakan untuk mengetahui mutu
bibit ataupun kualitas kemampuan
untuk adaptasi terhadap lingkungan.
IMB yang memenuhi standar agar dapat
bertahan hidup dan siap di tanam di
lapangan yaitu sebesar 0,09karena pada
nilai tersebut bibit mempunyai
kemampuan tumbuh yang lebih baik di
lapangan (Djamhuriet al.2012). Tabel 3
menunjukkan bahwa nilai indeks mutu
bibit pada setiap perlakuan belum
memenuhi standar mutu bibit kecuali
pada perlakuan tanpa naungan+pupuk
kimia yaitu 0,14. Hal ini berarti bahwa
cuka organik sebesar 4\% belum mampu
meningkatkan indeks mutu bibit pulai
selama 12 minggu, dapat dilihat dari
nilai bobot kering pucuk dan bobot
kering akarnya belum menunjukan
kesiapan bibit dilapangan.

\section{KESIMPULAN}

Berdasarkan hasil penelitian pada pengamatan variabel, cuka kayu tidak berpengaruh. Namun sub faktor nyata meningkatkan pertambahan tinggi dan jumlah daun dibandingkan cuka kayu, apabila bibit pulai ditanam dibawah kondisi tanpa naungan. Namun bila bibit pulai ditanam pada kondisi dengan
Pupuk

NPK Cuka kayu

Indeks Mutu Bibit

$0,14 \quad 0,05$

$0,8 \quad 0,05$

naungan $60 \%$, hanya cuka kayu yang nyata meningkatkan pertambahan jumlah daun.

\section{SARAN}

Penelitian selanjutnya disarankan untuk mencoba konsentrasi cuka kayu yang berbeda untuk mengetahui konsentrasi cuka kayu yang paling efektif apakah dibawah atau diatas 4\%. Diharapkan dari penelitian ini dapat diperoleh pengetahuan baru mengenai jenis pupuk organik yang baik bagi pertumbuhan tanaman tanpa harus menggunakan pupuk kimia.

\section{DAFTAR PUSTAKA}

Adinungraha HA. 2012. Pengaruh Cara Penyemaian dan Pemupukan NPK terhadap Pertumbuhan Bibit Mahoni Daun Lebar di persemaian. Jurnal Pemuliaan Hutan 6(2): 1-9.

Anonim. 2001. Wood vinegar. Forest Energy Forum No. 9. FAO.

Banjarnahor S, Artanti N. 2014. Antioxidant properties offlavonoids. Medical Journal of Indonesia, 23(4): 239-244).

Baherta. 2009. Pengaruh Tingkat Naungan dan Media Tanam Terhadap Persentase Pecah Mata Tunas dan Pertumbuhan Bibit 
Karet Okulasi Hijau.Jurnal Ilmiah Tambua 8(3): 467-472.

Badan Planologi Kehutanan. 2005. Rekalkulasi Penutupan Lahan Indonesia Departemen Kehutanan R.I Jakarta.

Djamhuri E, Yuniarti N, Purwani H. D. 2012. Viabilitas Benih dan Pertumbuhan Awal Bibit Acacia dari Lima Sumber Benih di Indonesia. Jurnal Silvikultur Tropika. 3(3): 187-195.

Dirdjosoemarto S. 1991. Penerapan Nilai Pertumbuhan Akar sebagai Tolok Ukur Mutu Bibit Beberapa Tanaman Industri. Laporan Penelitian Fakultas Kehutanan UGM. Yogyakarta. Tidak dipublikasikan.

Faridah E. 1996. Pengaruh intensitas cahaya,mikoriza dan serbuk arang pada pertum-buhan alam. Buletin Pene-litian, Fahutan UGM Yogyakarta, 29:21-28

Gaspersz V. 1991. Metode Perencanaan Percobaan. Bandung: CV Amino

Javid Q.A, Abbasi N. A, Saleem N 2005. Effect of NPK Fertilizer on Performance of Zinnia (Zinnia elegans) Wirlyging Shade. International Journal of Agriculture and Biology. 7(3): 471-473.

Komarayati S, Gustan P. 2014. Kombinasi Pemberian Arang Hayati Dan Cuka Kayu Terhadap Pertumbuhan Jabon Dan Sengon. Jurnal Hasil Hutan 32(1): 12-13.

Komarayati S, Gusmailina, pari G. 2013. Arang dan cuka kayu produk hasil hutan bukan kayu untuk meningkatkan pertumbuhan tanaman dan serapan hara karbon.
Jurnal penelitian hasil hutan 31(1): 49-62.

Komarayati S, Santoso E. 2011. Arang dan cuka kayu : Produk HHBK untuk stimulant pertumbuhan mengkudu. Jurnal Penelitian Hasil Hutan 29(2): 155-178

Marjenah. 2001. Pengaruh Perbedaan Naungan di Persemaian terhadap Pertumbuhan danRespon Morfologi Dua Jenis SemaiMeranti. Jurnal Rimba Kalimantan 6(2): 46-58.

Martawijaya, Rudjiman G.1993. Alstonia scholaris.R.Br, Plant Resources of South-East Asia. CABI Forestry Compendium. Jurnal Penelitian Hutan Tanaman 201 (2): 1-8.

Mindawati N, Yusnita S. 2005. Pengaruh Macam Media terhadap Pertumbuhan Semai Acacia mangiumWilld. Jurnal Penelitian Hutan dan Konservasi Alam 2(1): 53-59.

Oliet. 2004. Mineral nutrition and growth of containerized Pinus halepensis seedlings under controlled-release fertilizer. Scienteia Horticulturae 103:129113.

Pratiwi. 2000. Potensi dan Prospek Pengembangan Pohon Pulai untuk Hutan Tanaman .Jurnal Penelitian Kehutanan dan Perkebunan 1 (1): 1-9.

Rochamayanto Y, Darusaman D, Rusolono T. 2010. Perubahan Kandungan Karbon dan Nilai Ekonominya Pada Konversi Hutan Rawa Gambut Menjadi Tanaman Industri. Jurnal Tanaman Hutan 7(2): 93-106. 
JURNAL HUTAN LESTARI (2019)

Vol. 7 (3) : 1321 - 1327

Sumarna Y. 2008. Pengaruh media dan pupuk NPK terhadap pertumbuhan bibit pohon penghasil gaharu karas (Aquilaria malaccensis Lamk.). Jurnal Penelitian Hutan dan Konservasi Alam 2(2): 1993-1999.

Ting IP. 1982. Plant Physiology. Philippines: Addisson Wesley Publikasi.

Yulianti.2007. Pemberian Naungan Dapat Menurunkan Suhu Udara dan Meningkatkan Kelembaban. Jurnal Agrista 16(1): 12-20.

Yatagai M. 2002. Utilization of charcoal and wood vinegar in Japan. Graduate School of Agricultural and Life Sceinces. The University of Tokyo. Japan. Jurnal Hasil Penelitian Hutan 27 (4): 337-351. 